Research Article

\title{
Enhancing Activity of Pd-Based/rGO Catalysts by Al-Si-Na Addition in Ethanol Electrooxidation in Alkaline Medium
}

\author{
Minh Dang Nguyen (D), Lien Thi Tran, Quang Minh Nguyen, Thao Thi Nguyen, \\ and Thu Ha Thi Vu
} Key Laboratory for Petrochemical and Refinery Technologies, No. 2, Pham Ngu Lao Street, Hoan Kiem District,
Hanoi 100000, Vietnam

Correspondence should be addressed to Minh Dang Nguyen; nmd.hd.bk.13@gmail.com and Thu HaThiVu;ptntd2004@yahoo.fr Received 21 February 2019; Revised 30 May 2019; Accepted 12 June 2019; Published 23 June 2019

Guest Editor: Thanh-Dong Pham

Copyright (c) 2019 Minh Dang Nguyen et al. This is an open access article distributed under the Creative Commons Attribution License, which permits unrestricted use, distribution, and reproduction in any medium, provided the original work is properly cited.

\begin{abstract}
The article presents modified Pd-based catalysts supported on reduced graphene oxide (rGO), used in the electrooxidation reaction of ethanol in alkaline medium. When $\mathrm{NaBH}_{4}$ reducing agent was used, the random presence of $\mathrm{Na}$ was found out. According to this result, $\mathrm{Na}$ was used as a promoter of Pd-based catalyst. Consequently, the Al-Si-Na addition not only assisted active phase Pd nanoparticles to disperse homogenously on graphene surport, but also contributed to increase catalytic activity in the reaction. This value, $16138 \mathrm{~mA} \cdot \mathrm{mg}^{-1}$ Pd , is about 1.5 times higer than that of the catalyst modified by Al-Si. Moreover, the stability of the catalyst is enhanced more. The electrochemical stability of PASGN.N catalyst was relatively good: after 500 scanning cycles, the current density diminished $32 \%$ compared with the highest peak current density of the $15^{\text {th }}$ cycle, which was chosen as a reference. These significant improvement results in electrooxidation of ethanol have opened up the high potential application of these catalysts in direct-ethanol fuel cell.
\end{abstract}

\section{Introduction}

Nowadays, the direct ethanol fuel cell (DEFC) is one of the potential options for use in portable electronic devices, storage, and small electrical appliances. DEFC has high energy efficiency, remarkable efficiency in energy conversion, low temperature in operation, and considerable poison gas emissions. Moreover, producing ethanol from agricultural products and biomass fermentation process on a large scale is widely carried out $[1,2]$. However, in DEFC, noble metal-based catalysts, despite their good activity, are highly costly and easily poisoned by the adsorption process of the intermediate compounds formed during electrooxidation of ethanol. In addition, the electrode kinetics are sluggish $[3,4]$.

In the noble metal group, $\mathrm{Pd}$ and $\mathrm{Pt}$ had similar structure and electrochemical properties. However, for the electrooxidation of ethanol, Pd showed more advantages in comparison with Pt by the better resistance in alkaline medium, faster anionic film exchange capacity, and higher possibility of combination with other metals or transition metal oxides.

Some Pd-based catalysts such as Pd-Co [5], Pd-Ni [6-8], Pd-Ni-Sn [9], Pd-Ru-Ni [10], Pd-Cu [11], Pd-Au [12], Pd-Ag [13], or Pt-Pb [14] have been studied to minimize Pd content and poisoning effect in high electrochemical activity of remaining Pd. According to various researches, the presence of transition metals such as $\mathrm{Co}$ and $\mathrm{Ni}$, provided $\mathrm{M}-\mathrm{ROH}_{\mathrm{ads}}$ or formed $\mathrm{M}-(\mathrm{ROH})_{x}$ species (where $\mathrm{M}$ is the metal atom, $\mathrm{ROH}$ are methanol or ethanol), which changed the ethanol adsorption ability and enhanced the adsorption process of intermediate $\mathrm{CHO}_{\mathrm{ads}}, \mathrm{CO}_{\mathrm{ads}}$, limiting the poisoning process and thus improving the catalytic activity $[5-7,9,10]$.

On the other hand, choosing the support for Pd-based catalyst is an important factor that affects the electrochemical activity of catalyst. Carbon nanotubes (CNTs) and carbon black (Vulcan XC-72) are commonly used as support [15-18]. Recently, graphene materials have been attracting a 
high attention because of their advantages of physical and chemical properties such as electrical conductivity and a very high surface area $\left(\sim 2630 \mathrm{~cm}^{2} \cdot \mathrm{g}^{-1}\right)$ [19]. And, more especially, graphene enhances the dispersion of active metal particles.

In a recent research of Tan and colleagues [20], it was observed that the combination of $\mathrm{Pd}$ and $\mathrm{Ni}$ on graphene remarkably augmented catalytic activity of electrooxidation of ethanol in alkaline medium in comparison with $\mathrm{PdNi} / \mathrm{C}$ and Pd-Ni catalysts. Liu et al. [21] obtained similar results at the same conditions of the catalytic test for catalyst of $\mathrm{MnO}_{2}-$ promoted Pd supported on graphene oxide (GO) and multiwalled carbon nanotubes. This was explained by the few-layer structure, a high conductivity, and the large accessible area of GO which enhanced the interaction and dispersion of the $\mathrm{Pd}$-active phase on graphene surface. In addition, GO also contains oxygen-functional groups which are the combination site of metal ions, thereby increasing catalytic stability in the electrolyte medium.

In our paper [22], Si-Al was a very good bimetallic promoter phase in modified catalyst based on $\mathrm{Pt} / \mathrm{rGO}$ in methanol electrooxidation. The results in this paper showed that modified Pt-rGO with 7\% Si-Al was the best catalyst which had the highest activity in methanol electrooxidation with more than $1700 \mathrm{~mA} \cdot \mathrm{mg}^{-1}{ }_{\mathrm{Pt}}$ current density. The $\mathrm{Al}$ and $\mathrm{Si}$ compounds obtained in the catalyst exist as pseudoboehmite $(\mathrm{AlOOH})$ and silica $\left(\mathrm{SiO}_{2}\right)$, and they improve dispersion of the active phase on GO surface.

In this article, the preparation of $\mathrm{Pd} / \mathrm{rGO}$-based catalysts modified by promoters such as $\mathrm{Al}, \mathrm{Si}, \mathrm{Al}-\mathrm{Si}$, and $\mathrm{Al}-\mathrm{Si}-\mathrm{Na}$ and reduced by $\mathrm{NaBH}_{4}$ and ethylene glycol (EG) was reported. These catalysts are intended to be used as an anode catalyst for DEFC. These catalysts modified by promoters exhibited high activity in electrooxidation of ethanol in alkaline medium, and a highly improved resistance against poisoning of intermediary compounds in comparison with non-modified $\mathrm{Pd} / \mathrm{rGO}$ catalysts.

\section{Materials and Methods}

2.1. Chemicals. Exfoliated graphite was provided by SGL Carbon GmbH (GFG). Tetraethyl orthosilicate (TEOS) 99\%, aluminum tri-isopropoxide 99.9\%, $\mathrm{CH}_{3} \mathrm{COONa} 99 \%$, $\mathrm{NaOH} 98.8 \%, \mathrm{H}_{2} \mathrm{SO}_{4} 96 \%$, and ethanol $99.9 \%$ were purchased from Merck. And, Nafion ${ }^{\circledR}$ solution (whose mass fraction is $5 \%$ ), ethylene glycol (EG), sodium borohydrite $\left(\mathrm{NaBH}_{4}\right)$, isopropanol (IPA) $99.5 \%$, and $\mathrm{PdCl}_{2} 99 \%$ were purchased from Sigma Aldrich. The nitrogen gas of high purity (99.95\% (Air Liquide)) and deionized water were used in all experiments.

2.2. Catalyst Preparation and Characterization. GO slurry synthesized by the modified Hummers' method [23] was diluted to the content of $5 \mathrm{mg} \cdot \mathrm{mL}^{-1}$. Several catalysts based on graphene-supported palladium modified by metallic promoters were prepared in this study.

Sample of $28.57 \%$ Pd by active metal loadings (theoretically calculated, denoted as PG.E) and sample of $26.40 \%$ $\mathrm{Pd}-7.60 \% \mathrm{Na}$ (PNG.E) made from GO, EG, $\mathrm{CH}_{3} \mathrm{COONa}$, and $\mathrm{PdCl}_{2}$ were synthesized in the similar way of preparation of $40 \% \mathrm{Pt} / \mathrm{rGO}$ following a procedure described in [22].

In this catalyst, theoretical total mass fraction of $\mathrm{Al}$ and $\mathrm{Si}$ was $4.76 \%$ and mass fraction of $\mathrm{Pd}$ was $27.21 \%$. The $\mathrm{PdAlSiNa} / \mathrm{rGO}$ catalyst was reduced by EG as PASG.E catalyst with the addition of $\mathrm{CH}_{3} \mathrm{COONa}$ precursor (whose mass fraction of $\mathrm{Na}$ is $7.26 \%$ ) during the synthesis (denoted as PASNG.E).

The $\mathrm{PdAl} / \mathrm{rGO}$ and $\mathrm{PdSi} / \mathrm{rGO}$ catalysts reduced by EG (PAG.E and PSG.E) were synthesized in the similar way of preparation of PASG.EG catalysts but in absence of $\mathrm{Si}$ or $\mathrm{Al}$ precursors during synthesis, respectively. The theoretical elemental composition is $4.76 \mathrm{wt} \%$ of $\mathrm{Al}$ and $27.21 \mathrm{wt} \%$ of $\mathrm{Pd}$ in PAG.E catalyst, and $4.76 \mathrm{wt} \%$ of $\mathrm{Si}$ and $27.21 \mathrm{wt} \%$ of $\mathrm{Pd}$ in PSG.E catalyst.

All catalysts reduced by $\mathrm{NaBH}_{4}$ are $\mathrm{Pd} / \mathrm{rGO}, \mathrm{PdNa} / \mathrm{rGO}$, $\mathrm{PdAlSi} / \mathrm{rGO}$, and $\mathrm{PdAlSiNa} / \mathrm{rGO}$, respectively, were denoted as PG.N, PNG.N, PASG.N, and PASGN.N. The PASGN.N catalyst synthesis process was performed as follows: a precursor mixture of $18.8 \mathrm{~mL}$ of $\mathrm{PdCl}_{2} 0.01 \mathrm{M}$ and $10 \mathrm{~mL}$ of the solution GO $5 \mathrm{mg} \cdot \mathrm{mL}^{-1}$ was mixed and ultrasonicated for $2 \mathrm{~min}$ before adding $8.2 \mathrm{mg}$ Al-isopropoxide, $2 \mathrm{~mL}$ IPA, $20 \mu \mathrm{L}$ TEOS, and $34 \mathrm{mg} \mathrm{CH} \mathrm{CHONa}_{3}$. The obtained mixture was sonicated by probe ultrasonic for $2 \mathrm{~min}$. Then, $20 \mathrm{~mL}$ of $\mathrm{NaBH}_{4} 0.15 \mathrm{M}$ was slowly added into the mixture for $15 \mathrm{~min}$. The reaction mixture was continuously stirred for $15 \mathrm{~h}$ before being washed with distilled water. The final product was dried by using a vacuum oven at $80^{\circ} \mathrm{C}$ for 2 h. The PG.N, PNG.N, and PASG.N catalysts were synthesized by the same method as above with the addition of corresponding precursors.

Transmission electron microscope (TEM) JEOL JEM 2010 and scanning electron microscope (SEM) in a S-4800 microscope (Hitachi, Japan) were used to investigate the morphology and microstructure of catalysts. A LabRam HR (Horiba Jobin Yvon) spectrometer was operated to record Raman spectra. A KRATOS Axis Ultra DLD spectrometer was applied to perform the XPS analyser. The ICP-OES analyses were performed after pretreatment of the samples, in an ICP-OES ACTIVA (Horiba Jobin Yvon). The infrared spectrum of the samples, in the wavelength range of $400-$ $4000 \mathrm{~cm}^{-1}$, was measured on a Tensor 27-Bruker FTIR spectrometer. XRD patterns of the catalysts were measured on a D8 Advance (Bruker) apparatus. The process of these measurement preparations was clearly presented in [22].

2.3. Electrochemical Measurement. Electrochemical measurements were performed on a PGS-ioc-HH12 Potentiostat/Galvanostat electrochemical workstation (Institute of Chemistry-Vietnam Academy of Science and Technology). All experiments were conducted in a three-electrode system at room temperature: a glassy carbon working electrode (whose diameter is $5 \mathrm{~mm}$ ), a platinum counterelectrode, and an $\mathrm{Ag} / \mathrm{AgCl}$ reference electrode. The procedure of preparing catalyst ink was similar to the one described in [22]. The catalyst ink was prepared by dispersing $2 \mathrm{mg}$ of the catalyst powder in a mixture containing $0.9 \mathrm{~mL}$ ethanol and $0.1 \mathrm{~mL}$ Nafion solution $5 \mathrm{wt} \%$ under sonication for $30 \mathrm{~min}$. 
Electrochemical active surface area (EASA) measurements were carried out in $0.5 \mathrm{M} \mathrm{NaOH}$ aqueous solutions at a scan rate of $50 \mathrm{mV} \cdot \mathrm{s}^{-1}$, in the potential range of $-0.8 \mathrm{~V}$ to $0.5 \mathrm{~V}$.

Cyclic voltammetry was carried out in $(\mathrm{NaOH}$ $0.5 \mathrm{M}+\mathrm{C}_{2} \mathrm{H}_{5} \mathrm{OH} 1 \mathrm{M}$ ) aqueous solutions at a scan rate of $50 \mathrm{mV} \cdot \mathrm{s}^{-1}$, in the potential range of $-0.8 \mathrm{~V}$ to $0.5 \mathrm{~V}$. The chronoamperometric curves for the catalysts were recorded in a $\left(\mathrm{NaOH} 0.5 \mathrm{M}+\mathrm{C}_{2} \mathrm{H}_{5} \mathrm{OH} 1 \mathrm{M}\right)$ solution at a constant potential value of $-0.25 \mathrm{~V}$ (vs. $\mathrm{Ag} / \mathrm{AgCl}$ ) for $4000 \mathrm{~s}$.

\section{Results and Discussion}

Cyclic voltammograms and chronoamperometry curves in a $\left(\mathrm{NaOH} 0.5 \mathrm{M}+\mathrm{C}_{2} \mathrm{H}_{5} \mathrm{OH} 1 \mathrm{M}\right)$ solution at a room temperature for ethanol electrooxidation on $\mathrm{Pd} / \mathrm{rGO}$-based catalysts modified by different metals in ethylene glycol environment were introduced in Figure 1 and Table 1.

From the catalytic activity evaluation results for catalysts reduced by EG during synthesis, Pd-based catalyst that is nonmodified (PG.E) clearly showed a lower electrooxidation activity of ethanol than Pd-based catalyst modified by metal (see Figure 1(a)). Specifically, in alkaline medium, the activity of the catalysts is in ascending order as follows: PG.E $\quad\left(5369 \mathrm{~mA} \cdot \mathrm{mg}^{-1}{ }_{\mathrm{Pd}}\right)<$ PAG.E $\quad\left(5374 \mathrm{~mA} \cdot \mathrm{mg}^{-1} \mathrm{Pd}\right) \approx$ PSG.E $\left(5574 \mathrm{~mA} \cdot \mathrm{mg}^{-1}{ }_{\text {Pd }}\right)<$ PASG.E $\left(7822 \mathrm{~mA} \cdot \mathrm{mg}^{-1}\right.$ Pd $)($ see Table 1).

On the other side, the forward scanning peak current density (or called anodic current density) $-I_{\mathrm{F}}-$ means current density of ethanol electrooxidation on the electrode surface. And, the reverse scanning peak current density (or called cathodic current density) means current density in reduction of the oxygen group on the electrode surface. If $I_{\mathrm{F}} /$ $I_{\mathrm{R}}$ ratio and $I_{\mathrm{F}}$ are higher, ethanol eletrooxidation on electrode surface will happen more completely [24-27]. Therefore, in alkaline medium, the Pd-based catalysts modified by monometallic such as $\mathrm{Al}$ and Si showed only a slight improvement of catalytic activity in comparison with PG.E (see Table 1). Meanwhile, the one modified by bimetallic Al-Si (PASG.E) showed a significant increase in activity, which indicates a positive synergistic effect with $\mathrm{Pd}$ of two metals.

Some intermediate species such as $\mathrm{CHO}_{\mathrm{ads}}$ and $\mathrm{CO}_{\mathrm{ads}}$ formed during the ethanol electrooxidation poisoned the catalysts, which explained why all catalysts display an initial fast current decay in the chronoamperometry test (see Figure 1(b)). It is noted that the PASG.E catalyst exhibited better activity and resistance against poisoning by intermediate compounds in comparison with other catalysts reduced by EG during synthesis. After $4000 \mathrm{~s}$ of working, the current density of the PASG.E catalyst was $104.4 \mathrm{~mA} \cdot \mathrm{mg}^{-1}$ dd , significantly higher than that of PG.E catalysts $\left(21.6 \mathrm{~mA} \cdot \mathrm{mg}^{-1}\right.$ Pd $)$, PAG.E $\left(48.1 \mathrm{~mA} \cdot \mathrm{mg}^{-1}{ }_{\mathrm{Pd}}\right)$, and PSG.E (34.35 mA $\cdot \mathrm{mg}^{-1}{ }_{\text {Pd }}$ ). These remarkable results may be explained by the presence of pseudoboehmite $(\mathrm{AlOOH})$ and silica $\left(\mathrm{SiO}_{2}\right)$ that preferentially prevented the adsorption of toxic intermediate and/or formed products on the surface of catalyst, leading to the increase in the number of available catalytic site for reactants.
Thus, the addition of the metal as promoter phase in general, and the bimetallic phase Al-Si in particular, increased the electrochemical activity and also significantly improved resistance against poisoning of intermediate compounds of $\mathrm{Pd} / \mathrm{rGO}$ catalysts reduced by EG agent.

The content of noble metals and other elements in the catalysts was determined by the ICP-OES characterization and shown in Table 2. It is interesting to note that the mass fraction of Pd found in most catalysts is approximately $10 \%$, compared to the theoretical value of Pd ranging from $25 \%$ to $28 \%$. The mass fraction of other metals was measured from $0.2 \%$ to $2.7 \%$. The Pd loading of the catalysts reduced by $\mathrm{NaBH}_{4}$ is higher than that reduced by EG. Especially, the ICP-OES measurement showed the presence of $\mathrm{Na}$ in all catalysts reduced by $\mathrm{NaBH}_{4}$.

The valence state and surface composition of PASG.N catalyst were determined by X-ray photoelectron spectroscopy (XPS) measurements (see Figure 2). Figure 2(a) presents the XPS spectrum included the characteristic peaks of C 1s, O 1s, Al 2s, Al 2p, Si 2s, and Si 2p. Accordingly, $\mathrm{Al}$ and $\mathrm{Si}$ existing at the $\mathrm{Al}$ and $\mathrm{Si}$ compounds obtained in the catalysts exist as pseudoboehmite $(\mathrm{AlOOH})$ and amorphous silica $\left(\mathrm{SiO}_{2}\right)$ [22]. In addition, a characteristic peak of Pd 3d is also observed on the spectrum. Especially, the random appearance of $\mathrm{Na} 1 \mathrm{~s}$ and $\mathrm{Na}$ KLL that corresponds with the ICP results may be an important fator to augment activity of PASG.N catalyst.

Moreover, an intense peak of the $\mathrm{C} 1 \mathrm{~s}$ core level was observed in the XPS spectrum of rGO (see Figure 2(c)). After the deconvolution, two major peaks were identified and assigned as $\mathrm{sp}^{2} \mathrm{C}=\mathrm{C}$ at $284.4 \mathrm{eV}$ (due to the graphitic carbon), $\mathrm{sp}^{3} \mathrm{C}-\mathrm{O}$ at $285.8 \mathrm{eV}$ and $289.4 \mathrm{eV}$ (due to the hydroxyl and epoxy groups with graphene framework) [28].

Figure 2(b) shows the Pd 3d core level XPS spectrum of PASG.N catalyst which is resolved into $3 \mathrm{~d}_{5 / 2}$ and $3 \mathrm{~d}_{3 / 2}$ doublets caused by spin-orbital coupling [28]. The Pd 3d signals for catalysts can be deconvoluted into two pairs of doublets, which can be attributed to metallic Pd (0) and Pd (II). The deconvolution energies for $\mathrm{Pd}(0)$ and $\mathrm{Pd}$ (II) were at 335.7 and $340.9 \mathrm{eV}$, and $336.7 \mathrm{eV}$ and $342.6 \mathrm{eV}$, respectively. Metallic Pd phase was proved to be the major contribution as the intensities of Pd (II) were quite lower than those of Pd (0). It means that reducing from Pd (II) to $\operatorname{Pd}(0)$ reaction has happened successfully.

Besides, the relative signal intensities of $\mathrm{Pd}(0)$ and $\mathrm{Pd}$ (II) of PASG.N catalyst were different, $53.56 \%$ and $37.81 \%$, respectively. In addition, the $\mathrm{Pd}$ weight density on the catalyst surface was $8.23 \%$, while that of $\mathrm{Al}, \mathrm{Si}$, and $\mathrm{Na}$ was $2.38 \%, 3.44 \%$, and $2.19 \%$, respectively, which are similar to ICP results. It means that Pd nanoparticles were dispersed evenly both inside and outside of the catalyst. Moreover, the ratio between Pd (0) and Pd (II) PASG.N in XPS result of PASG.N, approximately 1.41, is higher than that of PASG.E, approximately 1.01 . This may be a cause of the different electrochemical activity of these catalysts.

In fact, when the agent $\mathrm{NaBH}_{4}$ was used instead of EG, the catalyst presented more catalytic activity and resistance against poisoning of intermediate compounds. Specifically, with the bimetallic Al-Si promoter phase, catalyst reduced by 


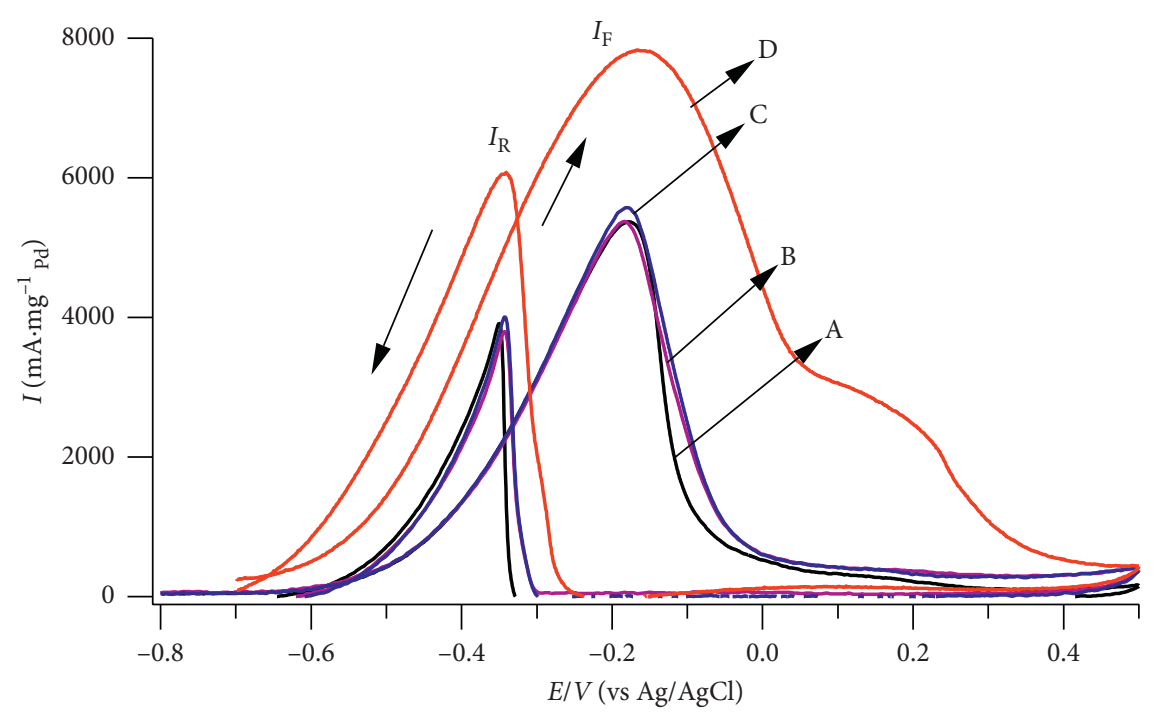

(a)

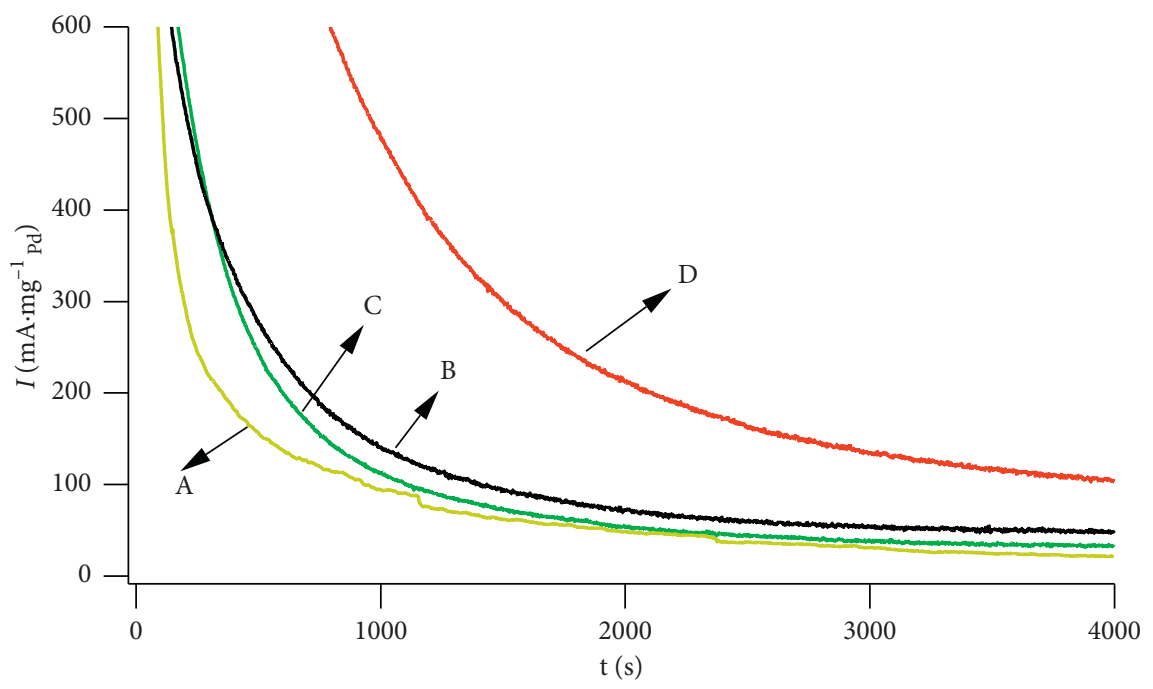

(b)

Figure 1: CV (a) and CA curves (b) of (A) PG.E, (B) PAG.E, (C) PSG.E, and (D) PASG.E catalysts in a $\left(\mathrm{NaOH} 0.5 \mathrm{M}+\mathrm{C}_{2} \mathrm{H}_{5} \mathrm{OH} 1 \mathrm{M}\right)$ solution at a scan rate of $50 \mathrm{mV} \cdot \mathrm{s}^{-1}$.

TABLE 1: CV results of Pd/rGO-based catalysts after 15 scanning cycles in a $\left(\mathrm{NaOH} 0.5 \mathrm{M}+\mathrm{C}_{2} \mathrm{H}_{5} \mathrm{OH} 1 \mathrm{M}\right)$ solution at a scan rate of $50 \mathrm{mV} \cdot \mathrm{s}^{-1}$.

\begin{tabular}{lccc}
\hline Catalyst & $I_{\mathrm{F}}\left(\mathrm{mA} \cdot \mathrm{mg}^{-1} \mathrm{Pd}\right)$ & $I_{\mathrm{R}}\left(\mathrm{mA} \cdot \mathrm{mg}^{-1} \mathrm{Pd}\right)$ & $I_{\mathrm{F}} / I_{\mathrm{R}}$ \\
\hline PG.E & 5369 & 3915 & 1.37 \\
PAG.E & 5374 & 3799 & 1.41 \\
PSG.E & 5574 & 4010 & 1.39 \\
PNG.E & 6988 & 5273 & 1.33 \\
PASG.E & 7822 & 6111 & 1.28 \\
PASNG.E & 8800 & 4367 & 2.02 \\
PG.N & 7457 & 3967 & 1.88 \\
PNG.N & 8357 & 4687 & 1.78 \\
PASG.N & 10705 & 5531 & 1.94 \\
PASGN.N & 16138 & 7949 & 2.03 \\
\hline
\end{tabular}

$\mathrm{NaBH}_{4}$ (PASG.N) showed 1.4 times higher activity than by EG (PASG.E) (see Table 1). In addition, after $4000 \mathrm{~s}$ of working, the current density of the PASG.N catalyst was 6.5 times higher than that of PASG.E. Furthermore, both electrochemical activity and the ratio of the forward scanning peak current density to the reverse scanning peak current density, $\left(I_{\mathrm{F}} / I_{\mathrm{R}}\right)$ of the PASG.N catalyst (1.93), were also higher than those of the PASG.E catalyst (1.28). Consequently, $\mathrm{NaBH}_{4}$ could be a better agent for Pd-based catalyst reduction than EG.

Na presence may cause increasing adsorption of oxygen and fuel on surface of the catalyst [29], which brings out increase of catalytic activity. To evaluate the role of $\mathrm{Na}$, the electrochemical activity of catalysts with and without addition of $\mathrm{Na}$ during synthesis for both EG and $\mathrm{NaBH}_{4}$ reducing agents was investigated (see Figure 3(a) and Table 1). It is obvious that whatever reducing agents were used during synthesis $\left(\mathrm{EG}\right.$ or $\mathrm{NaBH}_{4}$ ), all Na-doped catalysts showed significantly higher electrocatalytic activity compared with the non-Na-doped catalysts. Therefore, the role of promoter of $\mathrm{Na}$ was completely independent of the effect of the 
TABLE 2: ICP-OES results of Pd/rGO-based catalysts reduced by EG and $\mathrm{NaBH}_{4}$.

\begin{tabular}{|c|c|c|c|c|}
\hline \multirow[t]{2}{*}{ Catalysts } & \multicolumn{2}{|c|}{$\begin{array}{c}\text { Elemental mass fraction by ICP-OES } \\
\text { measurement }\end{array}$} & \multicolumn{2}{|c|}{ Theoretical elemental mass fraction } \\
\hline & $\mathrm{Pd}(\%)$ & Other metal (\%) & $\mathrm{Pd}(\%)$ & Other metals (\%) \\
\hline PG.E & 8.53 & - & 28.57 & - \\
\hline PNG.E & 7.51 & $2.52(\mathrm{Na})$ & 26.40 & $7.61(\mathrm{Na})$ \\
\hline PAG.E & 8.03 & $2.33(\mathrm{Al})$ & 26.40 & $7.61(\mathrm{Al})$ \\
\hline PSG.E & 7.86 & $2.54(\mathrm{Si})$ & 26.40 & $7.61(\mathrm{Si})$ \\
\hline PASG.E & 8.34 & $\begin{array}{l}0.34(\mathrm{Al}) \\
2.15(\mathrm{Si})\end{array}$ & 27.20 & $\begin{array}{l}1.36(\mathrm{Al}) \\
3.42(\mathrm{Si})\end{array}$ \\
\hline & & $2.40(\mathrm{Na})$ & & $7.25(\mathrm{Na})$ \\
\hline PASGN.E & 7.57 & $\begin{array}{c}0.27(\mathrm{Al}) ; \\
2.30(\mathrm{Si})\end{array}$ & 25.23 & $\begin{array}{c}1.26(\mathrm{Al}) ; \\
3.15(\mathrm{Si})\end{array}$ \\
\hline PG.N & 9.71 & $0.15(\mathrm{Na})$ & 28.57 & - \\
\hline PNG.N & 9.21 & $2.72(\mathrm{Na})$ & 26.40 & $7.61(\mathrm{Na})$ \\
\hline PASG.N & 8.78 & $\begin{array}{l}0.34(\mathrm{Al}) \\
2.41(\mathrm{Si}) \\
0.12(\mathrm{Na})\end{array}$ & 27.20 & $\begin{array}{l}1.36(\mathrm{Al}) \\
3.42(\mathrm{Si})\end{array}$ \\
\hline PASGN.N & 8.54 & $\begin{array}{c}2.62(\mathrm{Na}) \\
0.29(\mathrm{Al}) ; \\
1.83(\mathrm{Si})\end{array}$ & 25.23 & $\begin{array}{c}7.25(\mathrm{Na}) \\
1.26(\mathrm{Al}) \\
3.15(\mathrm{Si})\end{array}$ \\
\hline
\end{tabular}

reducing agent on the electrooxidation of ethanol. Moreover, the results obtained are also consistent with previous conclusions: catalysts modified by the Al-Si system owned a superior activity in comparison with $\mathrm{Pd} / \mathrm{rGO}$ catalysts and catalysts reduced by $\mathrm{NaBH}_{4}$, whose activities are much higher than those reduced by EG.

Besides, the poisoning resistance capacity of these catalysts in the electrochemical ethanol oxidation in alkaline mediums estimated by chronoamperometry (CA) (see Figure 3(b)) provided the same results. After $4000 \mathrm{~s}$ of working, the PASGN.N catalytic current density reached $680 \mathrm{~mA} \cdot \mathrm{mg}^{-1}{ }_{\mathrm{Pd}}\left(I_{\mathrm{F}}^{4000} \sim 32.27 \%\right.$ compared with the value of $\mathrm{CA}-I_{\mathrm{F}}^{0}$ at the beginning), 2.36 times higher than non-Nadoped PASG.N catalyst $\left(I_{\mathrm{F}}^{4000} \sim 17.85 \% . I_{\mathrm{F}}^{0}\right)$, and 6.1 times higher than Na-doped PASNG.E reduced by EG $\left(I_{\mathrm{F}}^{4000} \sim 15.64 \% . I_{\mathrm{F}}^{0}\right)$. Consequently, Na presence may assist the Pd-base catalysts in enhancing the resistance against poisoning of intermediate compounds in ethanol electrooxidation in alkaline media.

Figure 4 presents Raman spectra of GO and PASG.N catalyst. The peak intensities of the $\mathrm{G}$ band $\left(I_{\mathrm{G}}\right)$ at $\sim 1600 \mathrm{~cm}^{-1}$ corresponding to the $\mathrm{sp}^{2}$-hybrid carbon state in the hexagonal lattice of graphite and the $\mathrm{D}$ band $\left(I_{\mathrm{D}}\right)$ at $1350 \mathrm{~cm}^{-1}$ being characteristic for the vibration of $\mathrm{sp}^{3}$-hybrid $\mathrm{C}$ in the disorder structure of graphene sheets are clearly presented in [22]. The Raman spectra of catalysts were also similar to those of $\mathrm{GO}$, but the intensity of $I_{\mathrm{D}} / I_{\mathrm{G}}$ ratio of catalyst increased in the following order: GO (0.92) < PASG.N (1.02)< PASGN.N (1.10)< PASG.E (1.98). In addition, $I_{\mathrm{D}}>I_{\mathrm{G}}$ due to the presence of defects as well as the presence of Pd cluster, of metal or metal oxides on the graphene support $[20,30,31]$. This confirmed that the catalyst synthesis using chemical reduction process removes effectively the functional groups containing oxygen on the GO surface to form rGO.

FT-IR spectra of catalysts are shown in Figure 5. In the infrared spectra of graphene oxide, there are some characteristic vibration bands containing oxygen groups such as $\mathrm{O}-\mathrm{H}$ near $3500 \mathrm{~cm}^{-1}$ and around $1400 \mathrm{~cm}^{-1}, \mathrm{C}=\mathrm{O}$ at $1760 \mathrm{~cm}^{-1}$, and $\mathrm{C}-\mathrm{O}$ around $1100 \mathrm{~cm}^{-1}$, respectively. However, in that of PASGN.N catalyst, intensity of these peaks was reduced clearly. Moreover, the presence of $\mathrm{C}=\mathrm{C}$ bond near $1600 \mathrm{~cm}^{-1}$ was found out in the catalyst. Consequently, the reduction from GO to rGO was successful.

TEM images of the catalysts are introduced in Figure 6. The average particles size $d_{n}$ was calculated from particle size distribution using the following equation [32]:

$$
d_{n}=\frac{\sum n_{\mathrm{k}} d_{\mathrm{k}}}{\sum n_{\mathrm{k}}}
$$

where $n_{\mathrm{k}}$ is the frequency of occurrence of particles with size $d_{\mathrm{k}}$ from the TEM images.

The result showed that a less uniform and sparse dispersion of metallic nanoparticles are described for the catalysts. In addition, the PASG catalysts reduced by both EG and $\mathrm{NaBH}_{4}$ have a quite homogenous dispersion of active phase (dark spherical particles on rGO surface), but their sizes are different. For example, the PASG.N and PASGN.N catalysts (reduced by $\mathrm{NaBH}_{4}$ ) have their activity particle size from $7 \mathrm{~nm}$ to $14 \mathrm{~nm}$, while that of PASG.E catalyst (reduced by ethylene glycol) was three times larger, about $20 \mathrm{~nm}$ to $36 \mathrm{~nm}$. It means that reducing agent $\mathrm{NaBH}_{4}$ is improving the size of the catalytic active phase particle. Furthermore, TEM images of the PASGN.N (Na-doped) (see Figure 6(c)) and PASG.N (non-Na-doped) (see Figure 6(b)) catalyst introduced that $\mathrm{Na}$-doped significantly enhanced the dispersion of metallic nanoparticles on graphene support surface. The metal nanoparticles of PASGN.N catalysts expanded with higher density than those of PASG.N catalyst, which explained the increase in the number of active sites on the surface of graphene support, considerably enhancing the catalytic activity of electrooxidation of ethanol. Moreover, the metal 


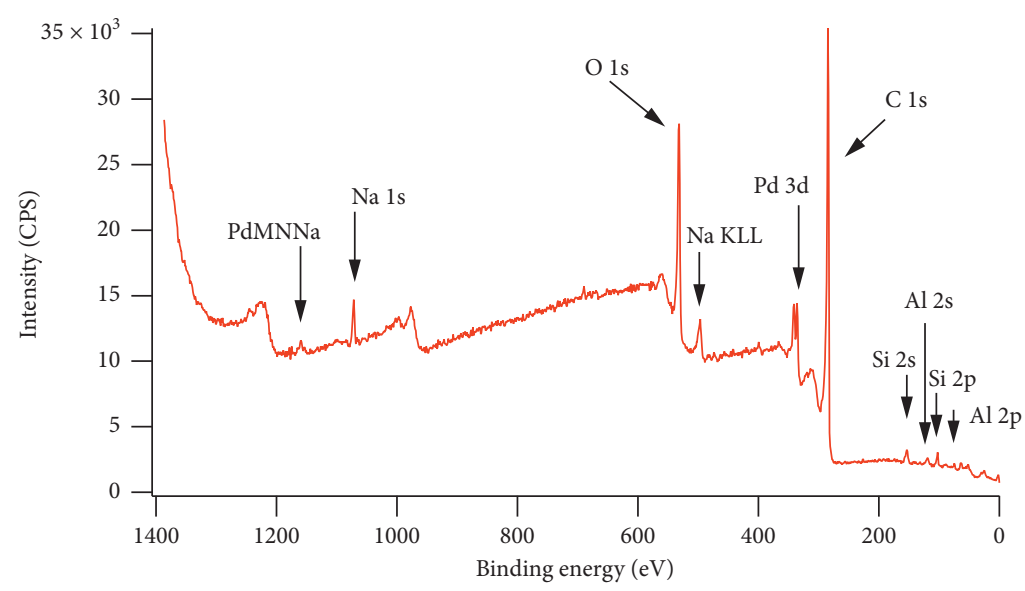

(a)

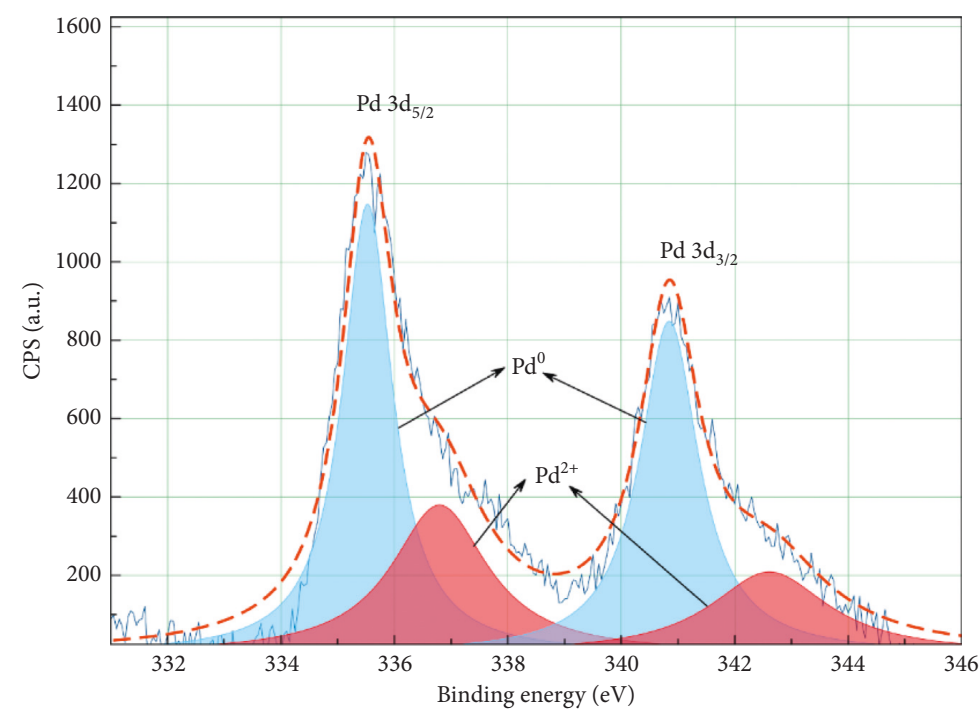

(b)

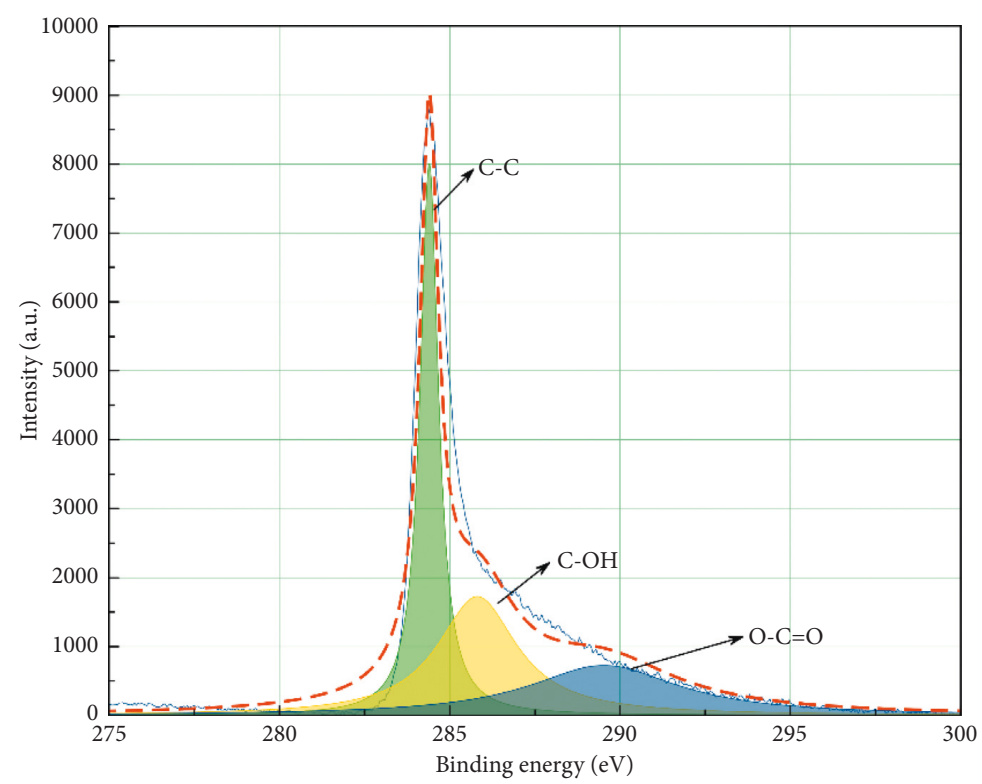

(c)

FIgURe 2: XPS spectrum (a), Pd 3d spectrum (b), and C 1s spectrum of the PASG.N catalyst (c). 


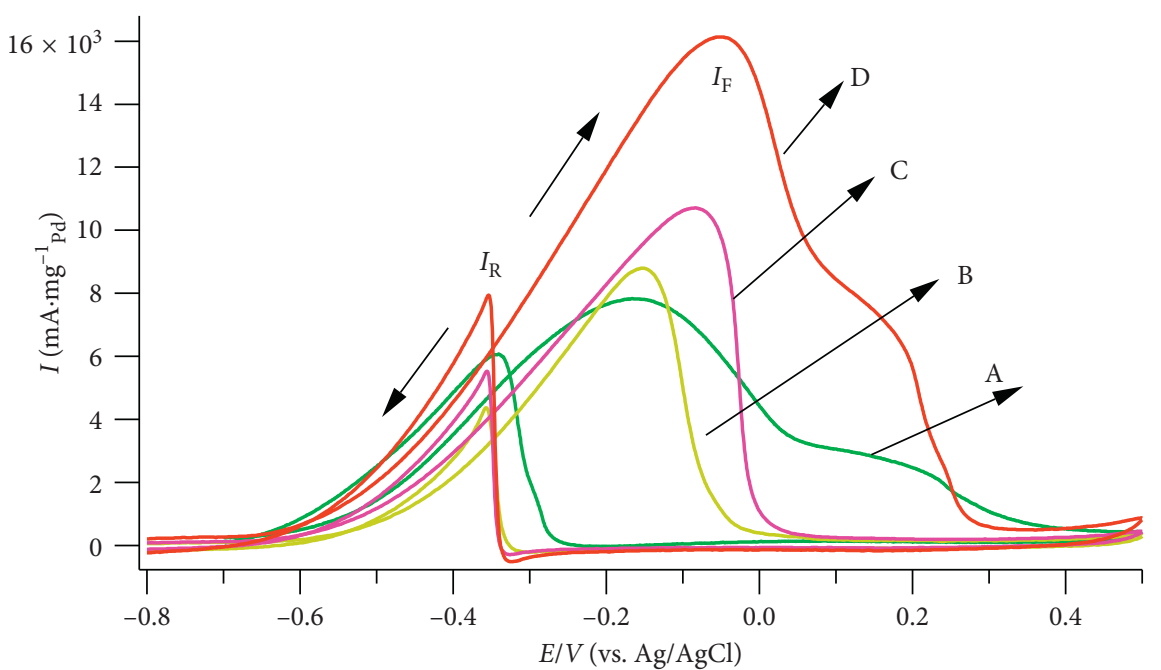

(a)

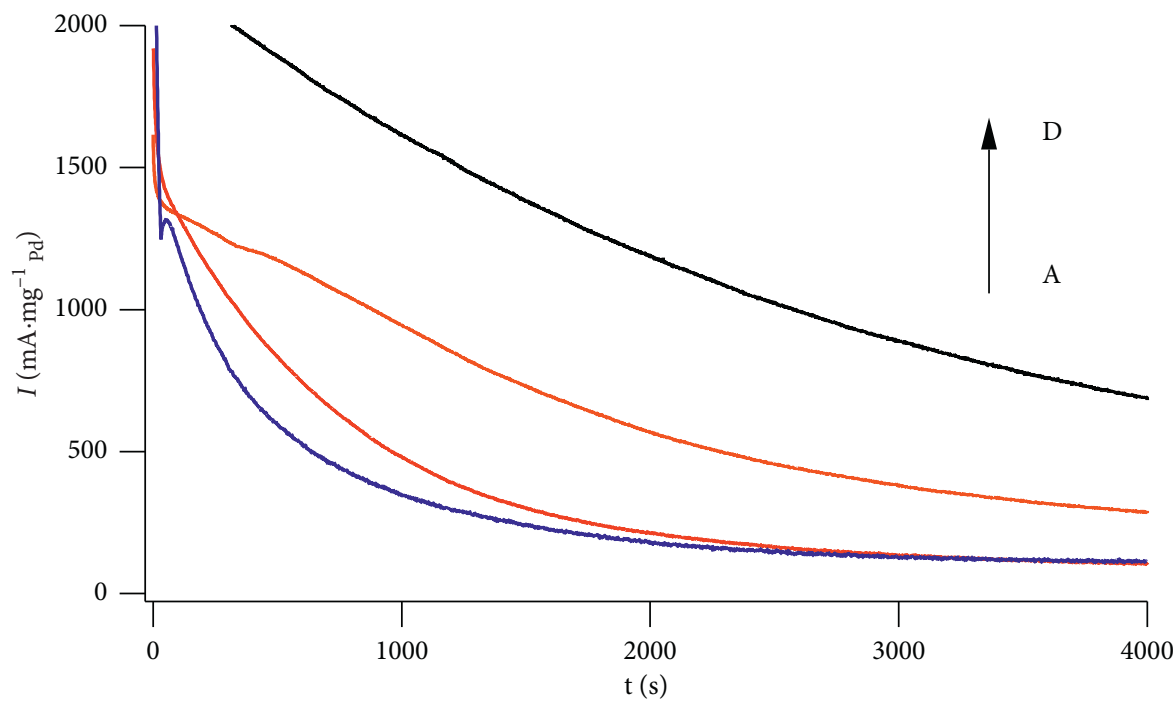

(b)

Figure 3: CV (a) and CA (b) curves of (A) PASG.E, (B) PASGN.E, (C) PASG.N, and (D) PASGN.N catalysts in a $\left(\mathrm{NaOH} 0.5 \mathrm{M}+\mathrm{C}_{2} \mathrm{H}_{5} \mathrm{OH}\right.$ $1 \mathrm{M})$ solution at a scan rate of $50 \mathrm{mV} \cdot \mathrm{s}^{-1}$.

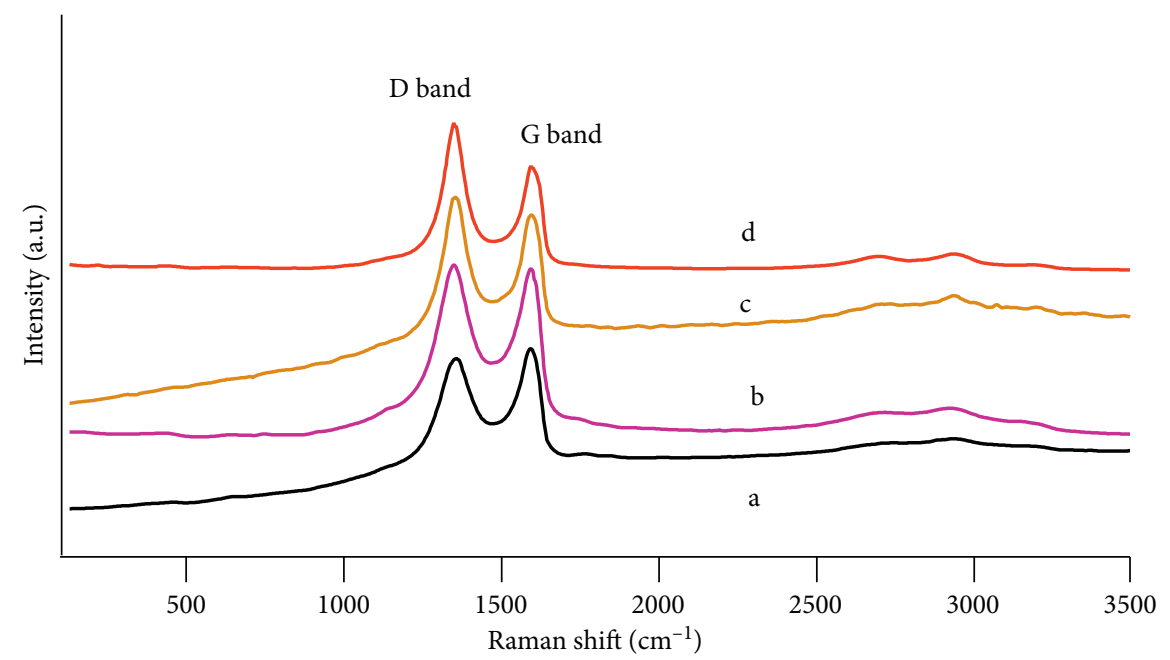

Figure 4: Raman spectra of (a) GO, (b) PASG.N, (c) PASGN.N, and (d) PASG.E. 


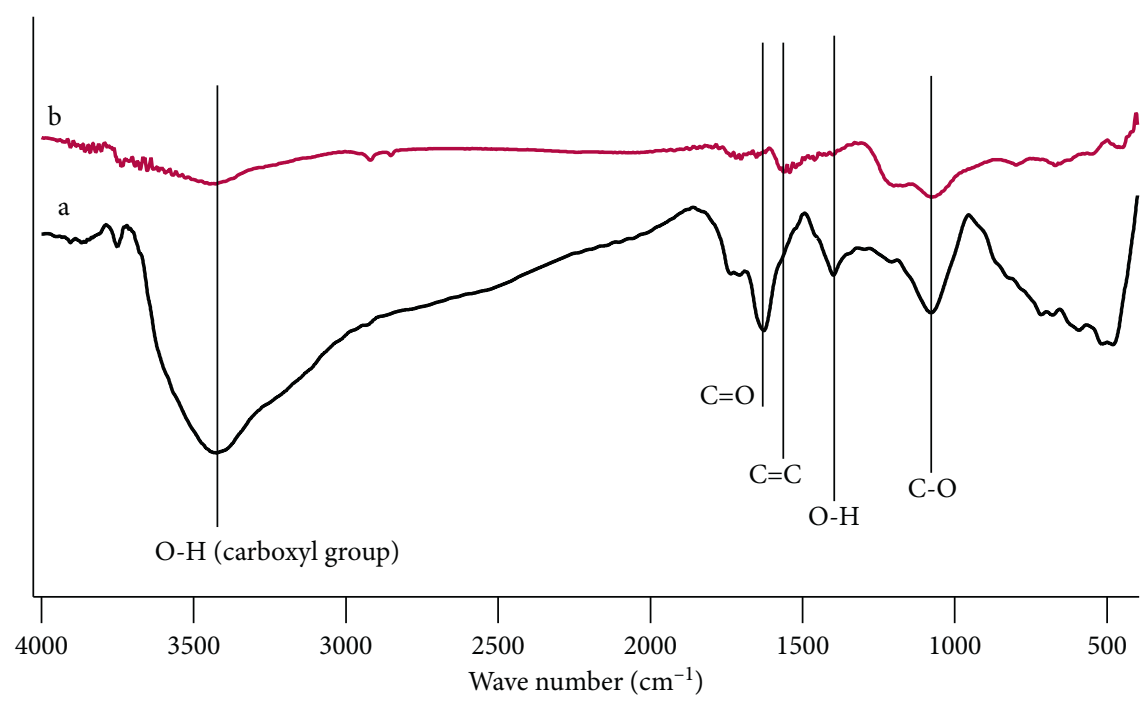

Figure 5: FTIR spectra of (a) GO and (b) PASGN.N.
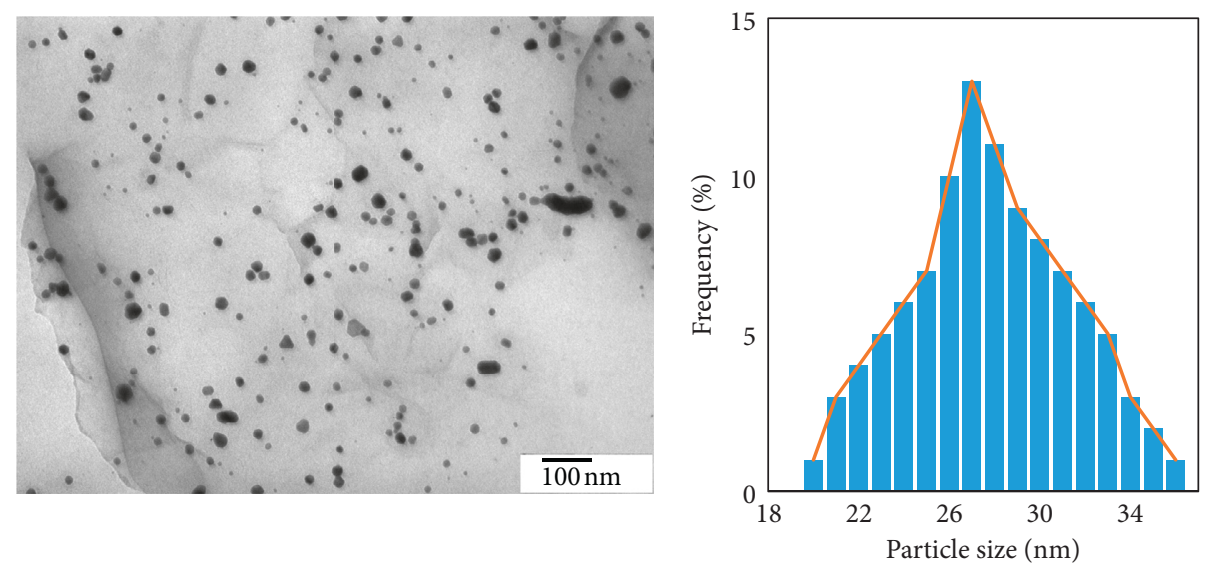

(a)
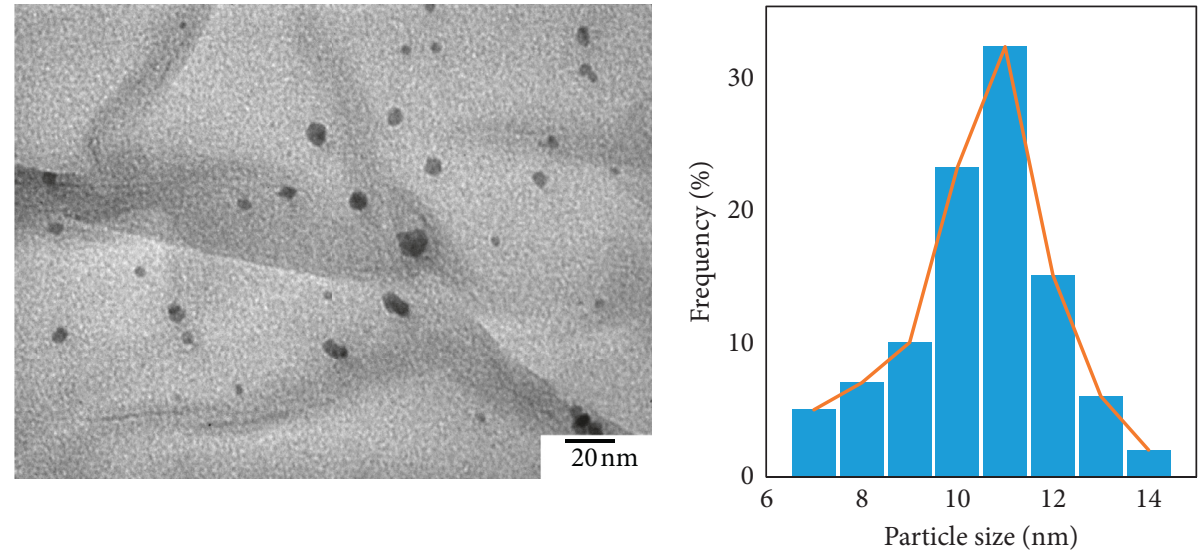

(b)

Figure 6: Continued. 

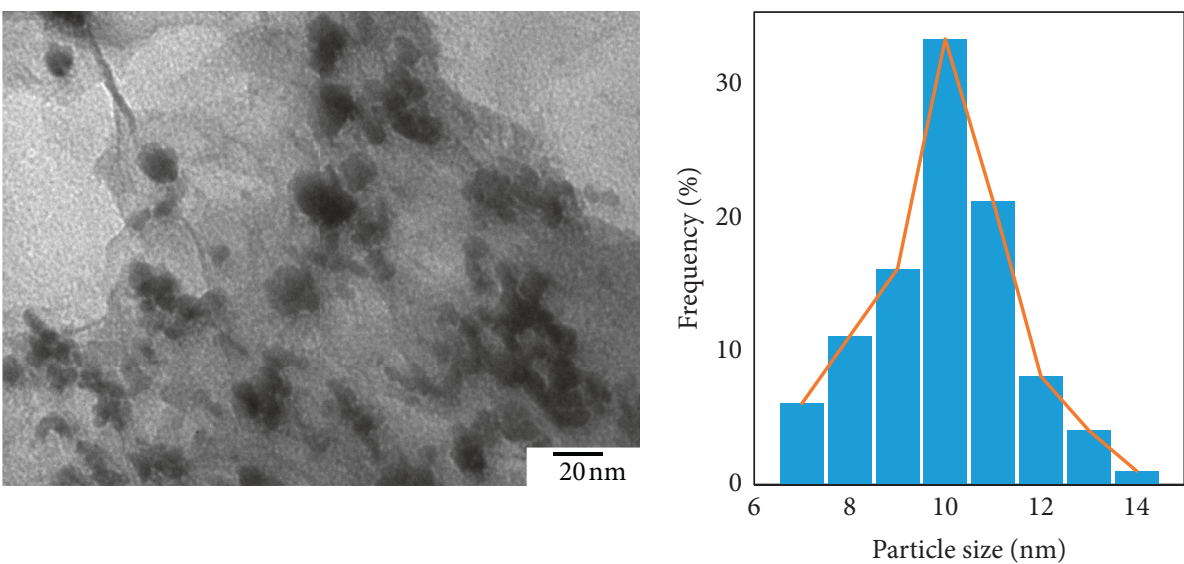

(c)

FIgURE 6: TEM images and particle size distributions of PASG.E (a), PASG.N (b), and PASGN.N (c) catalysts with different magnifications.

nanoparticles in the PASGN.N catalyst tend to aggregate from 2 to 3 particles to form larger ones at the edges of graphene sheets.

The EASA (electrochemical active surface area) of the Pd-based electrodes is determined by estimating the charge used in the reduction of palladium (II) oxide into palladium metal and using relation: $\mathrm{EASA}=Q / S$, where $Q$ is the Coulombic charge (in $\mathrm{mC}$ ) and $S$ is the proportionality constant which is taken $0.405 \mathrm{mC} \cdot \mathrm{cm}^{-2}$ in the case of reduction of a monolayer of PdO [4]. Average particles size $d_{n}$ and EASA are present in Table 3.

In fact, EASA of catalysts were in descending order as follows: PASG.E $\left(150.2 \mathrm{~m}^{2} \cdot \mathrm{g}^{-1}{ }_{\mathrm{Pd}}\right)<$ PASG.N $\left(193.7 \mathrm{~m}^{2} \cdot \mathrm{g}^{-1}{ }_{\mathrm{Pd}}\right)$ $<$ PASGN.N $\left(207.6 \mathrm{~m}^{2} \cdot \mathrm{g}^{-1} \mathrm{Pd}\right)$. This affection is similar to the TEM image described in Figure 6. The particles size is higher, the activity surface is lower [33].

On the other hand, the $\mathrm{Na}$ addition also improved stability of $\mathrm{Pb}$-based catalyst in ethanol electrooxidation. In order to study the catalytic lifetime of PASGN.N and PASG.N catalyst in alkaline medium, 500 cycles of a successive sweep from $-0.8 \mathrm{~V}$ to $0.5 \mathrm{~V}$ were carried out. The corresponding electrochemical activity results were noted in Table 4. The CV curve of the scanning cycles of PASGN.N catalyst was exhibited by the forward scanning peak current density in Figure 7. After the first 15 cycles to activate the catalysts, electrochemical activity of PASGN.N catalyst became stable. Therefore, the highest peak current density of the $15^{\text {th }}$ cycle $\left(I_{\mathrm{F}} 15^{\text {th }}\right)$ was chosen as a reference. After 200 cycles, the electrochemical activity of the catalysts decreased quite slowly where $I_{\mathrm{F}} 200^{\text {th }}$ was equal to $84 \%$ of the reference. The slow reactivity holds up to 500 cycles, where the forward current density value $I_{\mathrm{F}} 500^{\text {th }}$ was equal to $68 \%$ of the reference. Similarly, the electrochemical activity of PASG.N also decreased as the number of sweep rounds increased. However, the rate of decreasing catalytic activity of PASG.N is faster than that of PASGN.N (see Table 4), where its $500^{\text {th }}$ current density remained $27 \%$.

Besides, the combination between active phase (Pd nanoparticles) and support, graphene can become more
TABLE 3: EASA result of catalyst.

\begin{tabular}{lcc}
\hline Catalyst & Average particles size $(\mathrm{nm})$ & EASA $\left(\mathrm{m}^{2} \cdot \mathrm{g}^{-1} \mathrm{Pd}\right)$ \\
\hline PASG.E & 28.07 & 150.2 \\
PASG.N & 10.49 & 193.7 \\
PASGN.N & 9.97 & 207.6 \\
\hline
\end{tabular}

sustainable under the presence of Al-Si-Na addition, which is observed on TEM images of the catalysts after 500 scanning cycles (see Figure 8). For instance, in case of PASGN.N, the metal particles tend to aggregate into clusters of very large size, from $60 \mathrm{~nm}$ to $130 \mathrm{~nm}$, which dispersed in separate zones. The density of metallic nanoparticles on the graphene surface is also considerably reduced while that at the edges of graphene sheets tends to increase. However, in case of PASG.N catalyst, almost no metallic particles are presented on the surface of the graphene after 500 scanning cycles. This result is in accordance with the catalytic deactivation after 500 scanning cycles as described previously.

The morphology characteristic of PASGN.N catalyst before and after 500 scanning cycles were observed more clearly on the SEM image (see Figure 9). The result showed that the catalyst looked as a homogeneous "block;" however, it was broken to pieces after the reaction. Moreover, Figure 9(b) also shows the number of particles with columnar shape. It seems that the active phase Pd may be separated from support and may agglomerate after hundreds of cycles. As a result, catalytic activity was reduced.

Figure 10 presented XRD patterns of PASGN.N catalyst before and after 500 cycles of the reaction. The peak at $2 \theta$ value of $40.1^{\circ}$ corresponding to the planes Pd (111) $[34,35]$ was shown in the pattern of catalyst before the reaction (see Figure 10(a)) while two peaks of planes PdO (110) and PdO (103) [35] were introduced in the catalyst after the reaction. Consequently, PdO crystal is forming during the reaction. This may be a cause of reduction of the catalytic activity. 
TABLE 4: Forward current density of PASGN.N and PASG.N catalysts after 500 scanning cycles in a $\left(\mathrm{NaOH} 0.5 \mathrm{M}+\mathrm{C}_{2} \mathrm{H}_{5} \mathrm{OH} 1 \mathrm{M}\right)$ solution at a scan rate of $50 \mathrm{mV} \cdot \mathrm{s}^{-1}$.

\begin{tabular}{lcccccccc}
\hline \multirow{2}{*}{ Catalyst } & \multicolumn{8}{c}{ Forward current density $I_{\mathrm{F}}\left(\mathrm{mA} \cdot \mathrm{mg}^{-1}\right.$ Pd } \\
& $I_{\mathrm{F}} 15^{\text {th }}$ & $I_{\mathrm{F}} 100^{\text {th }}$ & $I_{\mathrm{F}} 100^{\text {th }} / I_{\mathrm{F}} 15^{\text {th }}$ & $I_{\mathrm{F}} 200^{\text {th }}$ & $I_{\mathrm{F}} 300^{\text {th }}$ & $I_{\mathrm{F}} 400^{\text {th }}$ & $I_{\mathrm{F}} 500^{\text {th }}$ & $I_{\mathrm{F}} 500^{\text {th }} / I_{\mathrm{F}} 15^{\text {th }}$ \\
\hline PASGN.N & 16138 & 14175 & 0.88 & 13816 & 12751 & 12342 & 10864 & 0.68 \\
PASG.N & 10705 & 9100 & 0.85 & 8565 & 6884 & 4956 & 2884 & 0.27 \\
\hline
\end{tabular}

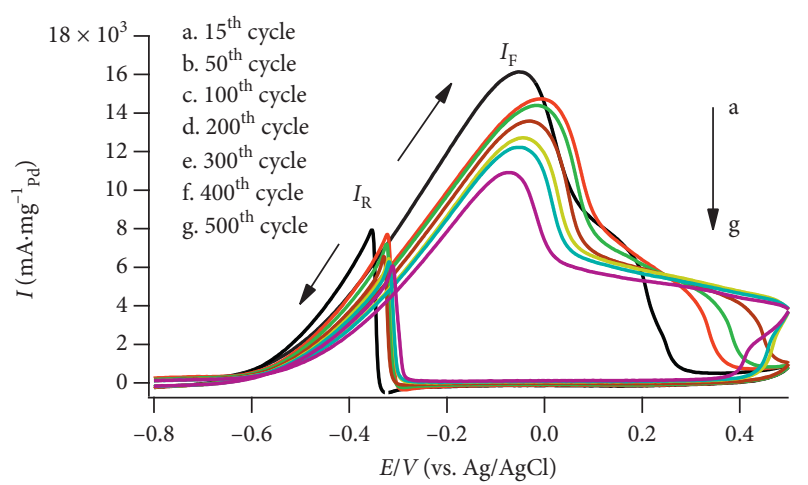

FIgURE 7: CV curves of catalytic PASGN.N after 500 scanning cycles in a $\left(\mathrm{NaOH} 0.5 \mathrm{M}+\mathrm{C}_{2} \mathrm{H}_{5} \mathrm{OH} 1 \mathrm{M}\right)$ solution at a scan rate of $50 \mathrm{mV} \cdot \mathrm{s}^{-1}$.

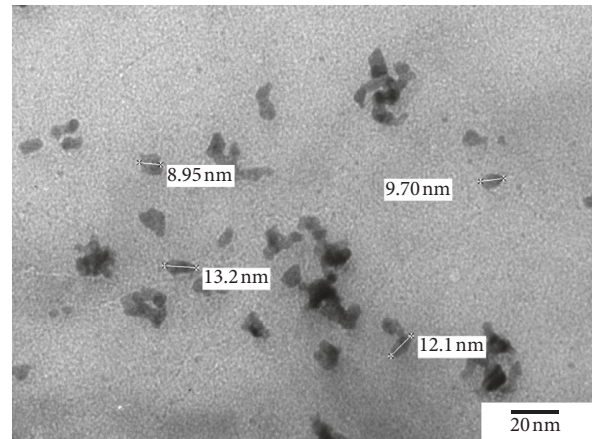

(a)

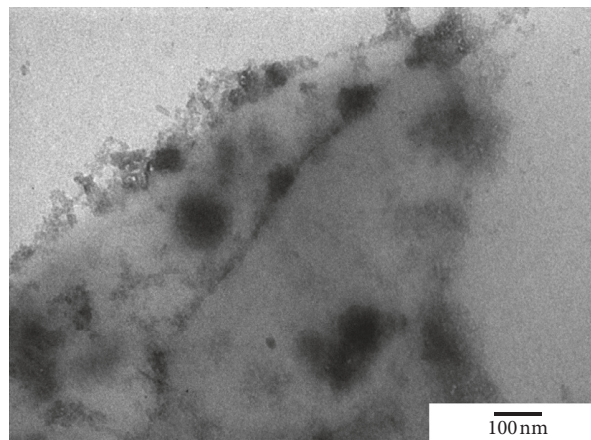

(c)

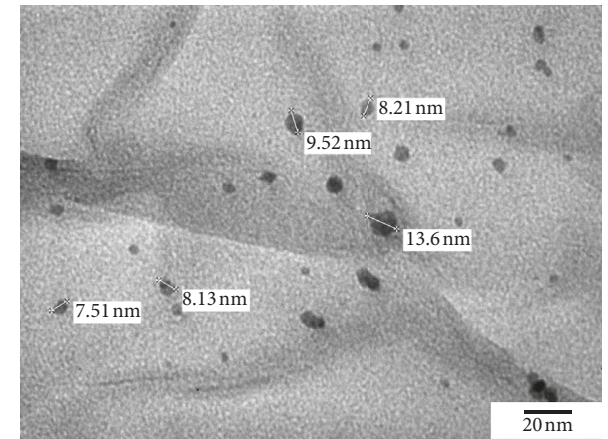

(b)

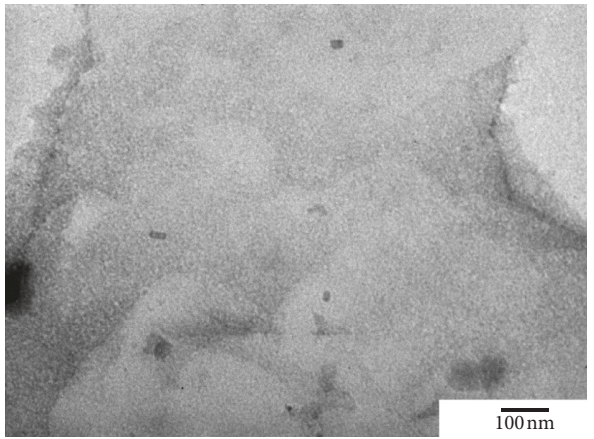

(d)

Figure 8: TEM images of PASGN.N and PASG.N catalysts before $(a, b)$ and after 500 scanning cycles $(c, d)$ in a $\left(\mathrm{NaOH} 0.5 \mathrm{M}+\mathrm{C}_{2} \mathrm{H}_{5} \mathrm{OH}\right.$ $1 \mathrm{M})$ solution at a scan rate of $50 \mathrm{mV} \cdot \mathrm{s}^{-1}$.

\section{Conclusion}

In conclusion, electrooxidation of ethanol was carried out on several Pd-based bimetallic or multimetallic catalysts supported on graphene. For all catalysts investigated, the role of promoting agents was confirmed when catalytic activity was enhanced in the presence of $\mathrm{Al}, \mathrm{Si}, \mathrm{Al}-\mathrm{Si}$, and $\mathrm{Al}-\mathrm{Si}$-Na. In addition, in comparison with the reducing 

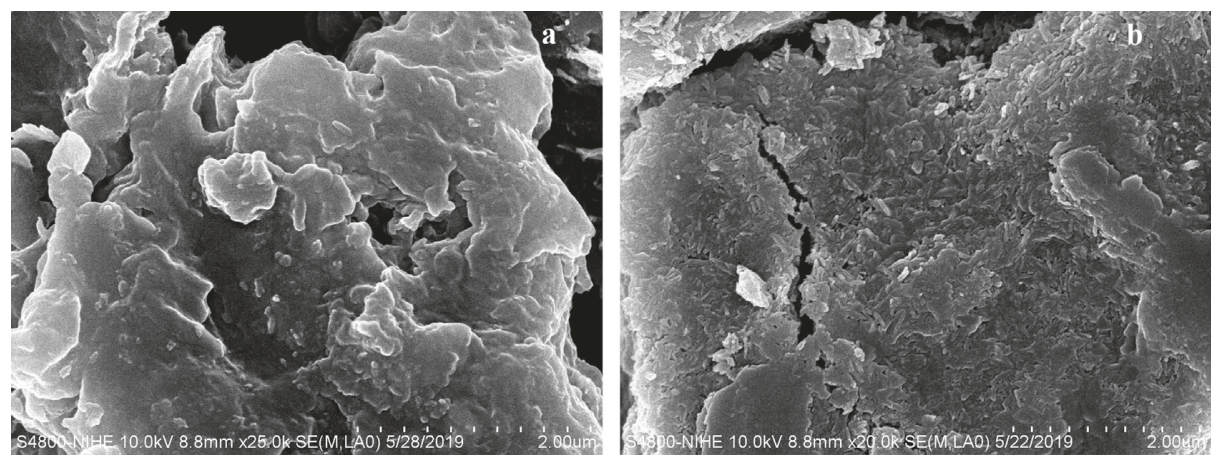

Figure 9: SEM images of PASGN.N catalysts before (a) and after (b) 500 scanning cycles in a $\left(\mathrm{NaOH} 0.5 \mathrm{M}+\mathrm{C}_{2} \mathrm{H}_{5} \mathrm{OH} 1 \mathrm{M}\right)$ solution at a scan rate of $50 \mathrm{mV} \cdot \mathrm{s}^{-1}$.

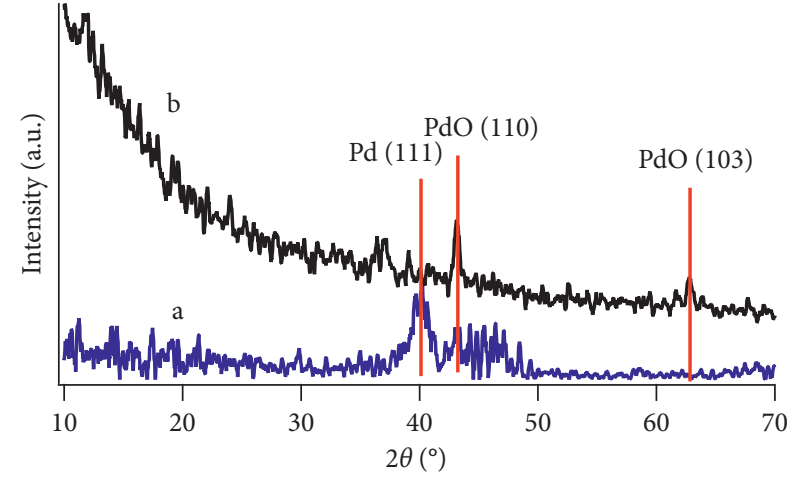

FIGURE 10: XRD patterns of PASGN.N catalysts before (a) and after (b) 500 scanning cycles in a $\left(\mathrm{NaOH} 0.5 \mathrm{M}+\mathrm{C}_{2} \mathrm{H}_{5} \mathrm{OH} 1 \mathrm{M}\right)$ solution at a scan rate of $50 \mathrm{mV} \cdot \mathrm{s}^{-1}$.

agent EG during synthesis, $\mathrm{NaBH}_{4}$ significantly not only improved the dispersion of metal nanoparticles on the support surface but also reduced crystalline size. As a result, catalytic electrochemical activity was increased. Specifically, PASGN.N catalysts presented the superior activity in electrooxidation of ethanol in the alkaline medium when the current density was more than $16000 \mathrm{~mA} \cdot \mathrm{mg}^{-1} \mathrm{Pd}$, which is the best results reported in this study. This value is higher than activity of Pd-based catalyst with different promoter $[20,36]$ or activity of Pt-base catalyst [37] with the same promoter. Another result in this particle is that the electrochemical stability of PASGN.N catalyst was relatively good: after 500 scanning cycles, the current density diminished $32 \%$ compared with the highest peak current density of the $15^{\text {th }}$ cycle. In conclusion, the obtained results have opened a new studying direction about synergistic effects of Al-Si-Na addition which both enhances activity and improves stability of Pd-based catalysts in ethanol electrooxidation in alkaline medium. In the same way, the content of noble metal is also reduced.

\section{Symbols}

$\begin{array}{ll}d_{\mathrm{k}}: & \text { Particle size } \\ d_{n}: & \text { Average particle size }\end{array}$
EASA: $\quad$ Electrochemical active surface area

FT-IR: Fourier transform infrared

ICP-OES: Inductively coupled plasma-optical emission spectrometry

$I_{\mathrm{D}}$ : $\quad$ Peak intensity of the $\mathrm{D}$ band in Raman spectra $/ \mathrm{cm}^{-1}$

$I_{\mathrm{F}}$ : $\quad$ Forward scanning peak current density in cyclic voltammetry curves $/ \mathrm{mA} \cdot \mathrm{mg}^{-1} \mathrm{Pd}$

$I_{\mathrm{F}} 15^{\text {th }}$ : Highest peak current density of the $15^{\text {th }}$ cycle in cyclic voltammetry curves $/ \mathrm{mA} \cdot \mathrm{mg}^{-1} \mathrm{Pd}$

$I_{\mathrm{F}} 200^{\text {th }}: \quad$ Peak current density of the $200^{\text {th }}$ cycle in cyclic voltammetry curves $/ \mathrm{mA} \cdot \mathrm{mg}^{-1} \mathrm{Pd}$

$I_{\mathrm{F}} 500^{\text {th }}$ : Peak current density of the $500^{\text {th }}$ cycle in cyclic voltammetry curves $/ \mathrm{mA} \cdot \mathrm{mg}^{-1} \mathrm{Pd}$

$I_{F}^{0}$ : $\quad$ Catalytic current density at the beginning in chronoamperometry curves $/ \mathrm{mA} \cdot \mathrm{mg}^{-1} \mathrm{Pd}$

$I_{F}^{4000 s}$ : Catalytic current density in chronoamperometry curves $/ \mathrm{mA} \cdot \mathrm{mg}^{-1} \mathrm{Pd}$

$I_{\mathrm{G}}$ : Peak intensity of the $\mathrm{G}$ band in Raman spectra/ $\mathrm{cm}^{-1}$

$I_{\mathrm{R}}: \quad$ Reverse scanning peak current density in cyclic voltammetry curves $/ \mathrm{mA} \cdot \mathrm{mg}^{-1} \mathrm{Pd}$

$n_{\mathrm{k}}: \quad$ Frequency of occurrence of particles

Q: $\quad$ Coulombic charge used in the reduction of palladium (II) oxide into palladium metal/mC

S: $\quad$ Proportionality constant in the case of reduction of a monolayer of $\mathrm{PdO} / \mathrm{mC} \cdot \mathrm{cm}^{-2}$

SEM: $\quad$ Scanning electron microscope

TEM: Transmission electron microscope

XPS: $\quad$ X-ray photoelectron spectroscopy

XRD: X-ray diffraction.

\section{Data Availability}

The data used in the study are available from the corresponding authors upon request.

\section{Additional Points}

Highlights. Nanocatalysts based on Pd/rGO were synthesized for the electro-oxidation of ethanol in alkaline medium. The random presence of $\mathrm{Na}$ was found out when reduced agent $\mathrm{NaBH}_{4}$ was used instead of EG. Al-Si-Na addition enhances the 
activity of Pd-base catalyst and improves its electrochemical stability after 500 scanning cycles. Al-Si-Na addition improves dispersion and combination of the active phase $\mathrm{Pd}$ on reduced graphene oxide surface. $\mathrm{NaBH}_{4}$-reducing $\mathrm{PdAlSiNa} / \mathrm{rGO}$ has the highest electrocatalytic activity, $16138 \mathrm{~mA} \cdot \mathrm{mg}_{\mathrm{Pd}}{ }^{-1}$.

\section{Conflicts of Interest}

The authors declare that there are no conflicts of interest regarding the publication of this paper.

\section{Acknowledgments}

The research and publication of our article was funded by the Project Management Unit of Fostering Innovation through Research, Science, and Technology (FIRST) for the subproject through grant agreement no. 06/FIRST/2a/KEYLABPRT and Ministry of Industry and Trade (MOIT) for the project no. ĐTKHCN.224/17. The authors gratefully acknowledge the financial supports from the Project Management Unit of Fostering Innovation through Research, Science, and Technology (FIRST) and Ministry of Industry and Trade (MOIT).

\section{References}

[1] Y. Li, W. Gao, L. Ci, C. Wang, and P. M. Ajayan, "Catalytic performance of Pt nanoparticles on reduced graphene oxide for methanol electro-oxidation," Carbon, vol. 48, no. 4, pp. 1124-1130, 2010.

[2] Q.-L. Zhang, J.-N. Zheng, T.-Q. Xu et al., "Simple one-pot preparation of Pd-on-Cu nanocrystals supported on reduced graphene oxide for enhanced ethanol electrooxidation," Electrochimica Acta, vol. 132, pp. 551-560, 2014.

[3] L. Dong, R. R. S. Gari, Z. Li, M. M. Craig, and S. Hou, "Graphene-supported platinum and platinum-ruthenium nanoparticles with high electrocatalytic activity for methanol and ethanol oxidation," Carbon, vol. 48, no. 3, pp. 781-787, 2010.

[4] R. Awasthi and R. N. Singh, "Graphene-supported Pd-Ru nanoparticles with superior methanol electrooxidation activity," Carbon, vol. 51, pp. 282-289, 2010.

[5] Y. Wang, Y. Zhao, J. Yin, M. Liu, Q. Dong, and Y. Su, "Synthesis and electrocatalytic alcohol oxidation performance of Pd-Co bimetallic nanoparticles supported on graphene," International Journal of Hydrogen Energy, vol. 39, no. 3, pp. 1325-1335, 2014.

[6] R. S. Amin, R. M. A. Hameed, and K. M. El-Khatib, "Microwave heated synthesis of carbon supported $\mathrm{Pd}, \mathrm{Ni}$ and $\mathrm{Pd}-\mathrm{Ni}$ nanoparticles for methanol oxidation in $\mathrm{KOH}$ solution," Applied Catalysis B: Environmental, vol. 148-149, pp. 557-567, 2014.

[7] R. S. Amin, R. M. Abdel Hameed, K. M. El-Khatib, and M. Elsayed Youssef, "Electrocatalytic activity of nanostructured $\mathrm{Ni}$ and Pd-Ni on Vulcan XC-72R carbon black for methanol oxidation in alkaline medium," International Journal of Hydrogen Energy, vol. 39, no. 5, pp. 2026-2041, 2014.

[8] C. A. L. Ricoa, J. G. Rosa, E. O. Ortega et al., "High performance of ethanol co-laminar flow fuel cells based on acrylic, paper and $\mathrm{Pd}-\mathrm{NiO}$ as anodic catalyst," Electrochimica Acta, vol. 207, pp. 164-176, 2016.

[9] S. Jongsomjit, P. Prapainainar, and K. Sombatmankhong, "Synthesis and characterisation of Pd-Ni-Sn electrocatalyst for use in direct ethanol fuel cells," Solid State Ionics, vol. 288, pp. 147-153, 2016.
[10] K. Charoen, C. Warakulwit, C. Prapainainar, A. Seubsai, M. Chareonpanich, and P. Prapainainar, "Optimization of metal atomic ratio of $\mathrm{Pd} x \mathrm{Ru}$ y Ni $\mathrm{z}$ on carbon support for ethanol oxidation," Applied Surface Science, vol. 421, pp. 2-17, 2017.

[11] Q. Dong, Y. Zhao, X. Han, Y. Wang, M. Liu, and Y. Li, "Pd/ $\mathrm{Cu}$ bimetallic nanoparticles supported on graphene nanosheets: facile synthesis and application as novel electrocatalyst for ethanol oxidation in alkaline media," International Journal of Hydrogen Energy, vol. 39, no. 27, pp. 14669-14679, 2014.

[12] Z.-Z. Yang, L. Liu, A.-J. Wang et al., "Simple wet-chemical strategy for large-scaled synthesis of snowflake-like PdAu alloy nanostructures as effective electrocatalysts of ethanol and ethylene glycol oxidation," International Journal of $\mathrm{Hy}$ drogen Energy, vol. 42, no. 4, pp. 2034-2044, 2016.

[13] Y.-G. Jo, S.-M. Kim, J.-W. Kim, and S.-Y. Lee, "Compositiontuned porous Pd-Ag bimetallic dendrites for the enhancement of ethanol oxidation reactions," Journal of Alloys and Compounds, vol. 688, pp. 447-453, 2016.

[14] R. Jana, U. Subbarao, and S. C. Peter, "Ultrafast synthesis of flower-like ordered $\mathrm{Pd} 3 \mathrm{~Pb}$ nanocrystals with superior electrocatalytic activities towards oxidation of formic acid and ethanol," Journal of Power Sources, vol. 301, pp. 160-169, 2016.

[15] F. Zhang, D. Zhou, and M. Zhou, "Ethanol electrooxidation on $\mathrm{Pd} / \mathrm{C}$ nanoparticles in alkaline media," Journal of Energy Chemistry, vol. 25, no. 1, pp. 71-76, 2016.

[16] C. Hu and X. Wang, "Highly dispersed palladium nanoparticles on commercial carbon black with significantly high electro-catalytic activity for methanol and ethanol oxidation," International Journal of Hydrogen Energy, vol. 40, no. 36, pp. 12382-12391, 2015.

[17] G. Yang, Y. Zhou, H.-B. Pan et al., "Ultrasonic-assisted synthesis of $\mathrm{Pd}-\mathrm{Pt} /$ carbon nanotubes nanocomposites for enhanced electro-oxidation of ethanol and methanol in alkaline medium," Ultrasonics Sonochemistry, vol. 28, pp. 192-198, 2016.

[18] W. Chen, Y. Zhang, and X. Wei, "Catalytic performances of $\mathrm{PdNi} / \mathrm{MWCNT}$ for electrooxidations of methanol and ethanol in alkaline media," International Journal of Hydrogen Energy, vol. 40, no. 2, pp. 1154-1162, 2015.

[19] M. D. Stoller, S. Park, Y. Zhu, J. An, and R. S. Ruoff, "Graphene-based ultracapacitors," Nano Letters, vol. 8, no. 10, pp. 3498-3502, 2008.

[20] J. L. Tan, A. M. De Jesus, S. L. Chua et al., "Preparation and characterization of palladium-nickel on graphene oxide support as anode catalyst for alkaline direct ethanol fuel cell," Applied Catalysis A: General, vol. 531, pp. 29-35, 2017.

[21] Q. Liu, K. Jiang, J. Fan et al., "Manganese dioxide coated graphene nanoribbons supported palladium nanoparticles as an efficient catalyst for ethanol electrooxidation in alkaline media," Electrochimica Acta, vol. 203, pp. 91-98, 2016.

[22] T. H. T. Vu, T. T. T. Tran, H. N. T. Le et al., "Pt-AlOOH-SiO $/$ graphene hybrid nanomaterial with very high electrocatalytic performance for methanol oxidation," Journal of Power Sources, vol. 276, pp. 340-346, 2015.

[23] W. S. Hummers and R. E. Offeman, "Preparation of graphitic oxide," Journal of the American Chemical Society, vol. 80, no. 6, 1339 pages, 1958.

[24] H. Mao, T. Huang, and A. Yu, "Surface noble metal modified $\mathrm{PdM} / \mathrm{C}(\mathrm{M}=\mathrm{Ru}, \mathrm{Pt}, \mathrm{Au})$ as anode catalysts for direct ethanol fuel cells," Journal of Alloys and Compounds, vol. 676, pp. 390-396, 2016.

[25] A. M. Hofstead-Duffy, D.-J. Chen, S.-G. Sun, and Y. J. Tong, "Origin of the current peak of negative scan in the cyclic 
voltammetry of methanol electro-oxidation on Pt-based electrocatalysts: a revisit to the current ratio criterion," Journal of Materials Chemistry, vol. 22, no. 11, pp. 5205-5208, 2012.

[26] D. Y. Chung, K.-J. Lee, and Y.-E. Sung, "Methanol electrooxidation on the Pt surface: revisiting the cyclic voltammetry interpretation," Journal of Physical Chemistry C, vol. 120, no. 17, pp. 9028-9035, 2016.

[27] Y. Zhao, X. Li, J. M. Schechter, and Y. Yang, "Revisiting the oxidation peak in the cathodic scan of the cyclic voltammogram of alcohol oxidation on noble metal electrodes," RSC Advances, vol. 6, no. 7, pp. 5384-5390, 2016.

[28] R. Krishna, D. M. Fernandes, A. Marinoiu, J. Ventura, C. Freire, and E. Titus, "Facile synthesis of well dispersed Pd nanoparticles on reduced graphene oxide for electrocatalytic oxidation of formic acid," International Journal of Hydrogen Energy, vol. 42, no. 37, pp. 23639-23646, 2017.

[29] N. Seriani, "Sodium promoter inducing a phase change in a palladium catalyst," Journal of Physical Chemistry C, vol. 116, no. 43, pp. 22974-22979, 2012.

[30] S. Yang, J. Dong, Z. Yao et al., "One-Pot synthesis of graphene-supported monodisperse Pd nanoparticles as catalyst for formic acid electro-oxidation," Scientific Reports, vol. 4, no. 1, article 4501, 2014.

[31] A. H. Al-Marri, M. Khan, M. R. Shaik et al., "Green synthesis of Pd@graphene nanocomposite: catalyst for the selective oxidation of alcohols," Arabian Journal of Chemistry, vol. 9, no. 6, pp. 835-845, 2016.

[32] Y. Fan, Y. Zhao, D. Chen, X. Wang, X. Peng, and J. Tian, "Synthesis of Pd nanoparticles supported on PDDA functionalized graphene for ethanol electro-oxidation," International Journal of Hydrogen Energy, vol. 40, no. 1, pp. 322-329, 2015.

[33] J. Perez, V. A. Paganin, and E. Antolini, "Particle size effect for ethanol electro-oxidation on $\mathrm{Pt} / \mathrm{C}$ catalysts in half-cell and in a single direct ethanol fuel cell," Journal of Electroanalytical Chemistry, vol. 654, no. 1-2, pp. 108-115, 2011.

[34] L. Wang, J.-J. Zhai, K. Jiang, J.-Q. Wang, and W.-B. Cai, "Pd-Cu/C electrocatalysts synthesized by one-pot polyol reduction toward formic acid oxidation: structural characterization and electrocatalytic performance," International Journal of Hydrogen Energy, vol. 40, no. 4, pp. 1726-1734, 2015.

[35] J. Lin, T. Mei, M. Lv, C. Zhang, Z. Zhao, and X. Wang, "Sizecontrolled $\mathrm{PdO} /$ graphene oxides and their reduction products with high catalytic activity," RSC Advances, vol. 4, no. 56, pp. 29563-29570, 2014.

[36] J. Ma, J. Wang, G. Zhang et al., "Deoxyribonucleic acid-directed growth of well dispersed nickel-palladium-platinum nanoclusters on graphene as an efficient catalyst for ethanol electrooxidation," Journal of Power Sources, vol. 278, pp. 43-49, 2015.

[37] L. T. Tran, Q. M. Nguyen, M. D. Nguyen, H. N. T. Le, T. T. Nguyen, and T. H. T. Vu, "Preparation and electrocatalytic characteristics of the Pt-based anode catalysts for ethanol oxidation in acid and alkaline media," International Journal of Hydrogen Energy, vol. 43, no. 45, pp. 20563-20572, 2018. 

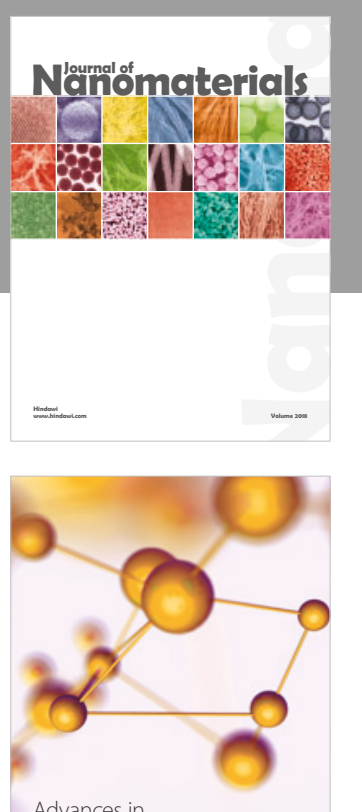

Physical Chemistry
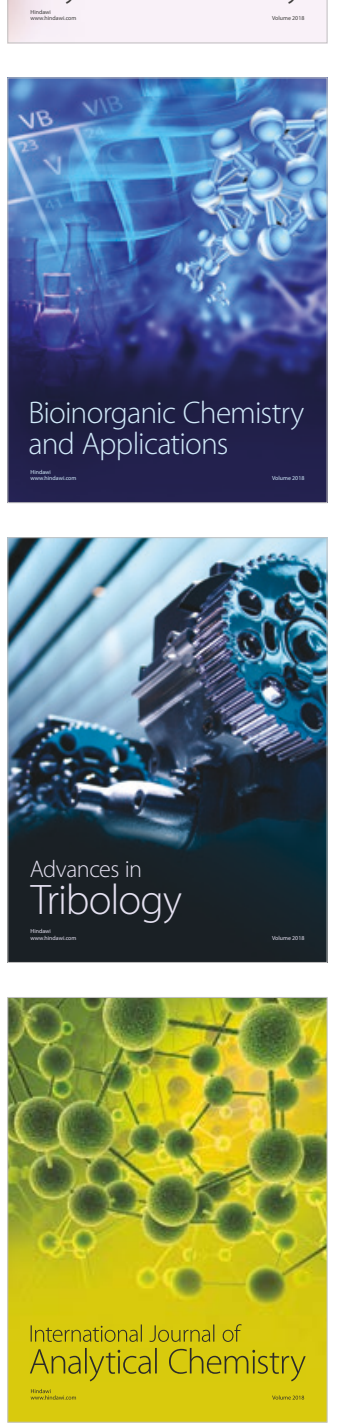

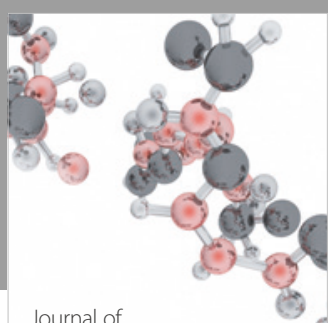

Analytical Methods

in Chemistry

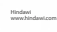

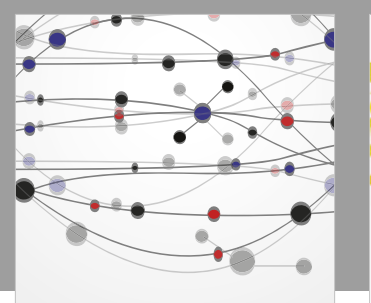

The Scientific World Journal

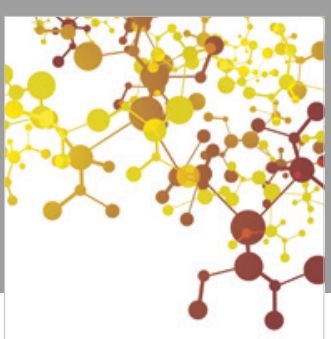

Journal of

Applied Chemistry
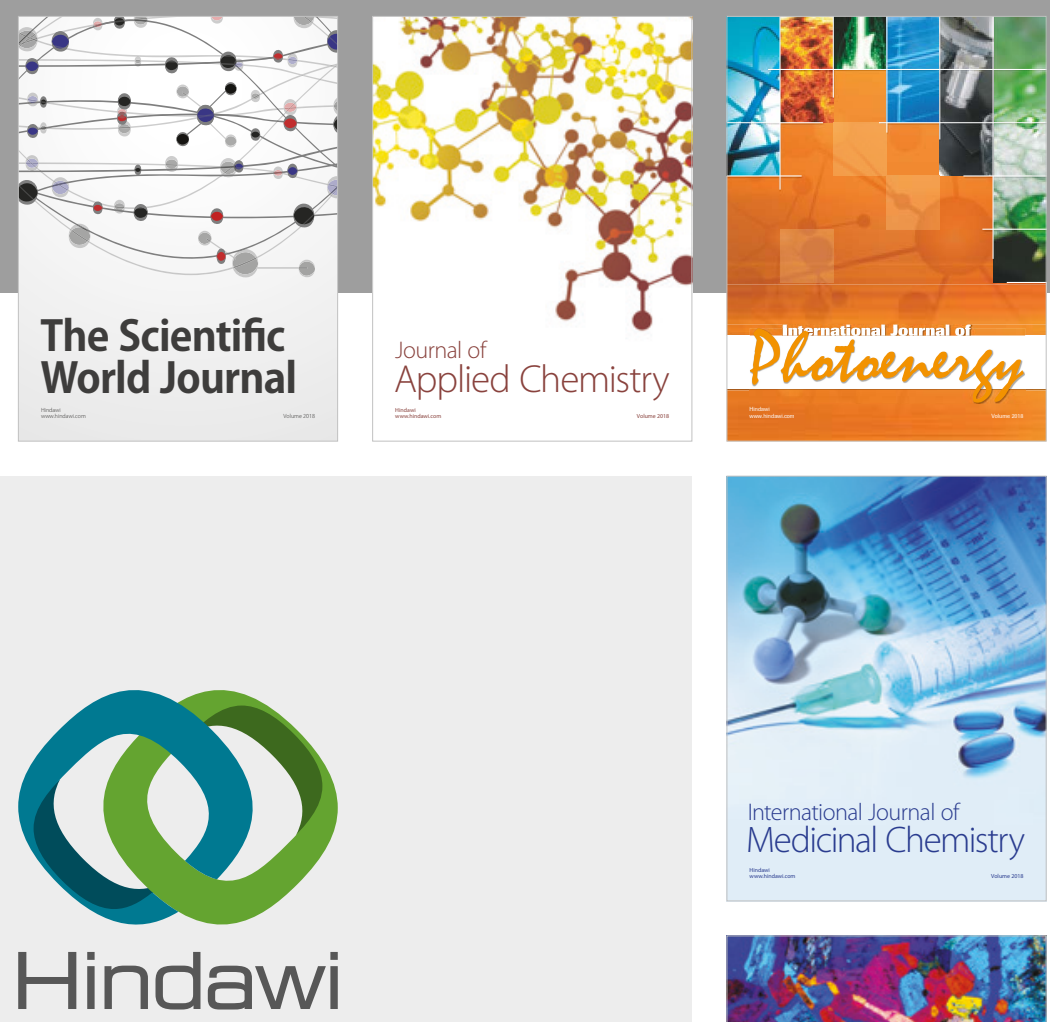

Submit your manuscripts at

www.hindawi.com
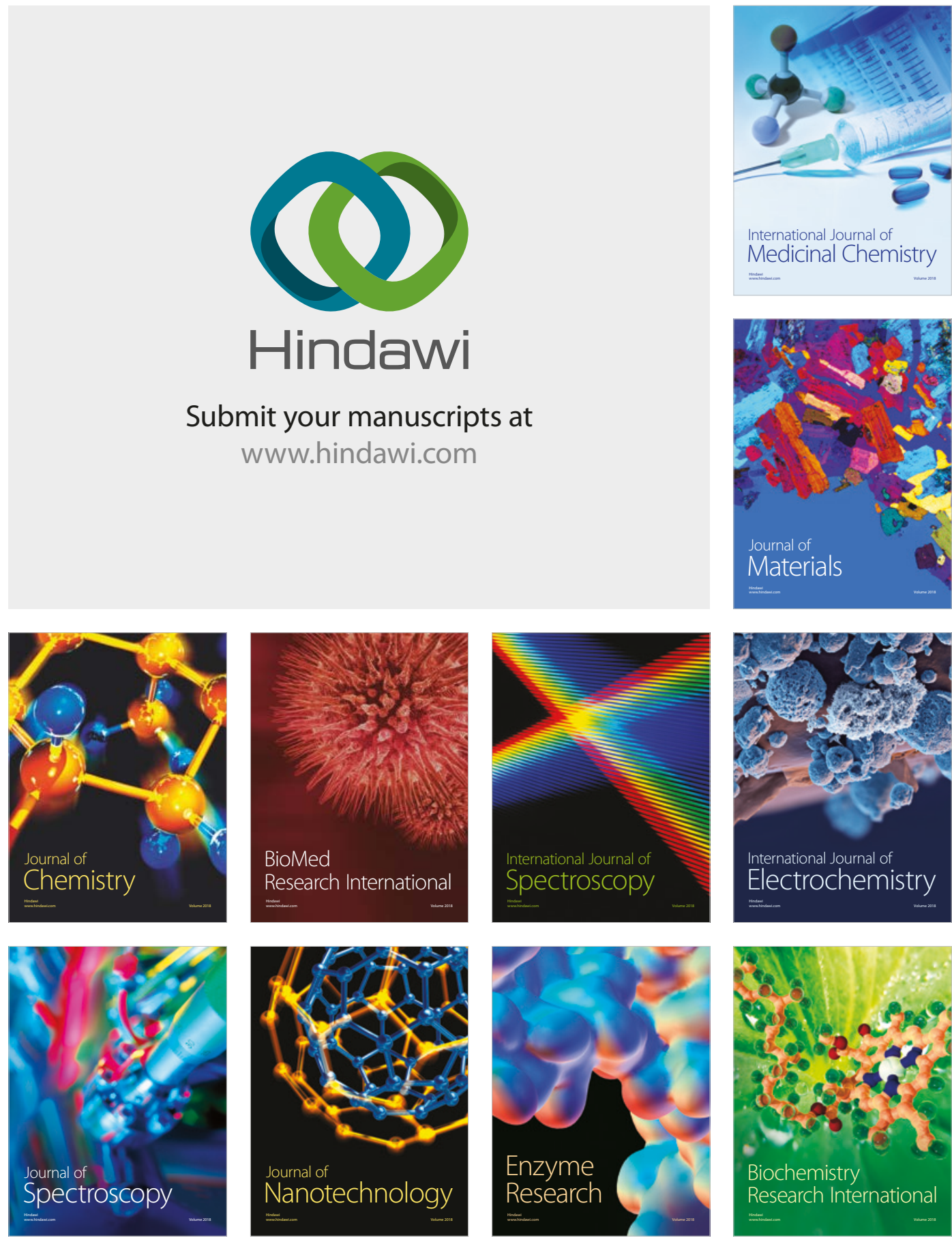
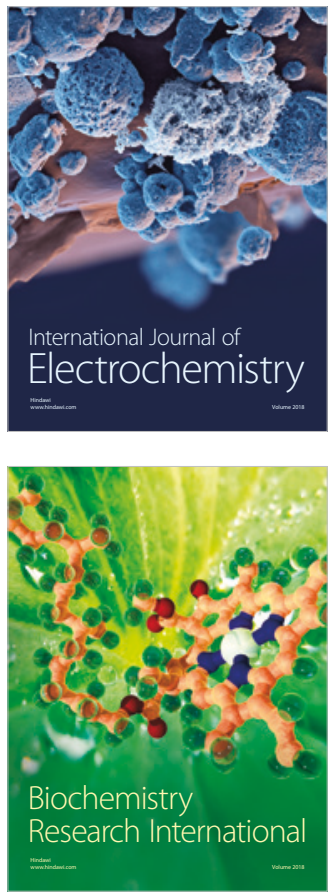